\title{
Critical threshold identified in the functional relationship between beaked whales and their prey
}

\author{
Kelly J. Benoit-Bird ${ }^{1, *}$, Brandon L. Southall ${ }^{2,3}$, Mark A. Moline ${ }^{4}$, \\ Diane E. Claridge ${ }^{5,6}$, Charlotte A. Dunn ${ }^{5,6}$, Karin A. Dolan ${ }^{7}$, David J. Moretti ${ }^{8}$ \\ ${ }^{1}$ Monterey Bay Aquarium Research Institute, Moss Landing, CA 95039, USA \\ ${ }^{2}$ Southall Environmental Associates, Inc., Aptos, CA 95003, USA \\ ${ }^{3}$ University of California, Santa Cruz, Long Marine Laboratory, Santa Cruz, CA 95060, USA \\ ${ }^{4}$ School of Marine Science and Policy, University of Delaware, Lewes, DE 19958, USA \\ ${ }^{5}$ Bahamas Marine Mammal Research Organisation, Marsh Harbour, Abaco, The Bahamas \\ ${ }^{6}$ University of St Andrews, Scottish Oceans Institute, St Andrews, Fife, KY16 8LB, UK \\ ${ }^{7}$ Naval Undersea Warfare Center, Newport, RI 02841, USA \\ ${ }^{8}$ Naval Undersea Warfare Center, Newport, RI 02841, USA (Retired)
}

\begin{abstract}
Anthropogenic noise is increasingly recognized as a potentially significant stressor for marine animals. Beaked whales, deep-diving cephalopod predators, have been disproportionally present in atypical mass stranding events coincident with military sonar exercises, while frequently disturbed populations that do not strand may have reductions in fitness. We present in situ measures of prey availability, a key factor affecting fitness, for 2 distinct populations of Mesoplodon densirostris: one on a US Navy range in The Bahamas and one nearby in an area less exposed to sonar. The variables most strongly correlated with beaked whale habitat use were related to the distribution of deep-sea squid (mode spacing, peak depth, and $100 \mathrm{~m}$ scale variability). All squid metrics were more favorable for beaked whales at the less exposed site than those on the range. To develop a generalized functional relationship between prey resources and beaked whale habitat use, data from The Bahamas were combined with comparable data from another Navy range and the larger beaked whale, Ziphius cavirostris. A powerlaw relationship was observed between a normalized metric of prey quality and whale habitat use. A critical threshold in prey characteristics, below which beaked whales appear unlikely to be successful, but above which small changes in resource availability enable large gains for predators, was observed. This implies that modest changes in the behavior of individual whales associated with disturbance can have consequential population effects. Our results elucidate the ecological realities of these elusive and sensitive beaked whales, and the importance of environmental context in effective spatial planning for the deep sea.
\end{abstract}

${ }^{*}$ Corresponding author: kbb@mbari.org

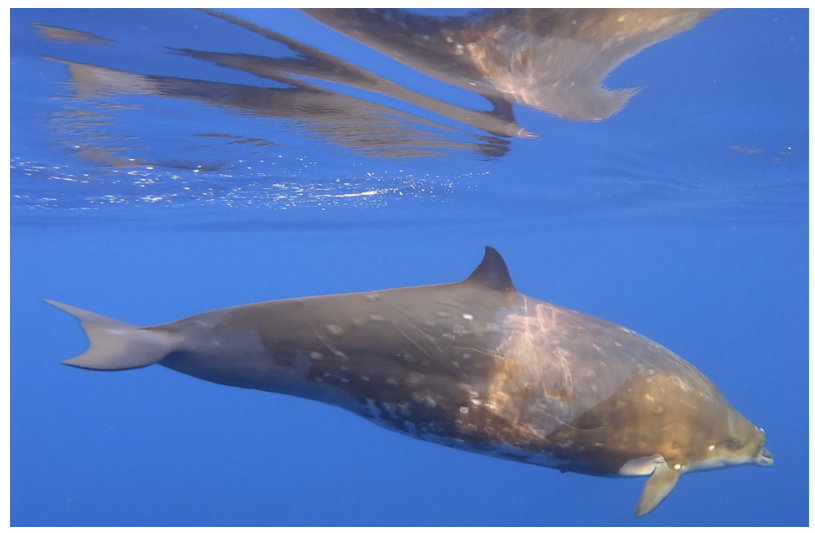

Mesoplodon densirostris, an elusive, deep-diving beaked whale, relies on newly described aggregations of squid in the deep sea to be successful.

Photo: Bahamas Marine Mammal Organisation

KEY WORDS: Beaked whales · Functional relationship · Predator-prey $\cdot$ Bathypelagic $\cdot$ Odontocete $\cdot$ Acoustics

\section{INTRODUCTION}

Large bodied, highly mobile predators can exert powerful effects on ecosystems (Ripple \& Beschta 2007, Ferretti et al. 2010). In marine communities, direct predation and behavioral changes driven by top-down forces have been shown to fundamentally shape ecosystems over large spatial and temporal

() Monterey Bay Aquarium Research Institute, Southall Environmental Associates, University of Delaware, Bahamas Marine Mammal Organisation 2020. Open Access under Creative Commons by Attribution Licence. Use, distribution and reproduction are unrestricted. Authors and original publication must be credited.

Publisher: Inter-Research · www.int-res.com 
scales (Springer et al. 2003, Worm \& Myers 2003, Heithaus et al. 2008) and even to modify the global carbon cycle (Huntley et al. 1991). High trophic level predators including sharks, large teleost fishes, marine mammals, and seabirds have been declining at a rapid pace in pelagic marine ecosystems, leading to significant ecosystem-level changes (Heithaus et al. 2008). These widespread marine predator declines have intensified attention on the many anthropogenic stressors these animals face, including direct hunting (Myers \& Worm 2003), bycatch in fisheries (Žydelis et al. 2009), competition with humans for resources (Cury et al. 2000, Smith et al. 2011), pollution (Maxwell et al. 2013), plastics (Choy \& Drazen 2013), and consequences of climate change (Veit et al. 1997, Hazen et al. 2013).

Over the last few decades, noise pollution has increasingly been recognized as a significant stressor for animals in the marine environment (e.g. Richardson et al. 2013, Simmonds et al. 2014, Southall 2017). The biological impacts of underwater anthropogenic noise from sources like shipping, fishing, oil and gas exploration, offshore construction, and military activities are complex, and our understanding is still developing (Simmonds et al. 2014). While intense noise exposure may cause injury or even death over short ranges, less intense but more broadly prevalent (in space and time) exposures can mask biologically important signals and cause behavioral disturbances with potential impacts on physiology and foraging success (Williams et al. 2015, Southall 2017). Odontocete cetaceans, or toothed whales, may be particularly susceptible to the effects of noise because of their reliance on active acoustic sensing (biosonar) coupled with their wide hearing bandwidth (Tyack \& Miller 2002).

Odontocete species of specific concern with regard to ocean noise include beaked whales, comprising 21 species of deep-diving cephalopod predators. There is considerable evidence of atypical mass stranding events of these species associated with military sonar exercises (Cox et al. 2006, Filadelfo et al. 2009). Recent evidence suggests that in addition to relatively rare mortality events, beaked whales that inhabit naval training ranges experience frequent behavioral disturbances including reduced dive rates and spatial displacement from preferred habitats (McCarthy et al. 2011, Moretti et al. 2014, Joyce et al. 2019). These behavioral changes likely have energetic and reproductive consequences which may lead to changes in population demographics (King et al. 2015, Hin et al. 2019). Bioenergetics models, for example, suggest that beaked whales require rela- tively high-quality habitat to meet their energy requirements, and that regular displacement from preferred feeding habitats could potentially impact survival and reproduction through compromised body condition (New et al. 2013). Understanding how these sublethal 'harassments' affect the population is mandated for activities likely to cause disturbance to species listed under protective statutes, including the US Marine Mammal Protection Act of 1972 (Roman et al. 2013). The energetic and demographic effects of disturbance on individuals and the populations of which they are part, however, can only be understood in the context of the local environment and the ecology of the species (Friedlaender et al. 2016). In fact, in models that integrate behavior and demographic data to predict population consequences of disturbance, environmental quality is among the most sensitive parameters (Southall et al. 2019). In pelagic marine ecosystems, however, controlled manipulations of environmental context are rarely possible, and data on the deep-sea habitats of beaked whales are scarce.

In addition to being regions of intense interaction between humans and numerous protected marine mammals, including beaked whales, US Navy undersea testing and training ranges provide a unique opportunity to study these elusive animals. Numerous cabled hydrophones within each Navy testing range have allowed for long-term monitoring of population dynamics, habitat use, foraging behavior, and response to human activities (Moretti et al. 2010, McCarthy et al. 2011, Tyack et al. 2011). One wellstudied population includes Blainville's beaked whales Mesoplodon densirostris (hereafter Mesoplodon) residing on the US Navy's Atlantic Undersea Test and Evaluation Center (AUTEC). Inhabiting a submarine canyon in The Bahamas known as the Tongue of the Ocean (TOTO), this population is repeatedly exposed to high levels of military activities, including sonar. Although there have been no recorded atypical stranding events at AUTEC (such as those described by Fernández et al. 2005, Cox et al. 2006), frequent disruptions and displacements off of the range (Joyce et al. 2019) may reduce the fitness of the population relative to a nearby population off Abaco Island that is less exposed to military sonar (Claridge 2013, Moretti 2019).

We present in situ measures of the availability of a key factor affecting animal fitness - food resources from the deep ocean on and near the AUTEC range. To inform ongoing efforts to incorporate environmental variability into population models for management of beaked whale species (New et al. 2013, 
Moretti 2019), we assessed whether underlying differences occurred in prey availability associated with concomitant and historical differences in habitat usage and published measures of population parameters. We compared these newly collected data with similar data collected on and around a test range located off Southern California that is home to Cuvier's beaked whales Ziphius cavirostris (hereafter Ziphius). The objective was to develop a generalized empirical relationship between a key environmental metric, prey availability, and habitat use by beaked whales in order to elucidate ecological relationships within this elusive family of whales and to inform deep-sea spatial planning.

\section{MATERIALS AND METHODS}

\subsection{Approach}

Data on deep-water biological resources in the waters around The Bahamas were collected using echosounders on 2 platforms: a purpose-built, deepdiving, autonomous underwater vehicle (AUV) and a research vessel. Together, these platforms provided measurements of acoustic scattering over nearly the full diving range of foraging Mesoplodon (Johnson et al. 2004, Baird et al. 2006, Johnson et al. 2008). These data were analyzed following Benoit-Bird et al. (2016) to provide estimates of integrated prey biomass, the number of separable individual prey, individual prey size, and relative composition of the prey field as well as descriptions of the distributional characteristics of these resources. To examine the effects of the multiple prey characteristics on beaked whale potential energetic gains, we followed the Southall et al. (2019) approach to integrate these metrics, tuned to the subject predator species in The Bahamas with available behavioral and energetic data to provide a simple, relativistic assessment of foraging habitat quality. We used this foraging habitat quality metric to compare the suitability of resources for Mesoplodon across sampling areas in and near the AUTEC range.

We also used the foraging habitat quality metric to synthesize measurements from The Bahamas with those collected similarly over deep waters in the Southern California Bight (Benoit-Bird et al. 2016, Southall et al. 2019). The area to the west of San Clemente Island off the coast of Southern California hosts the Southern California Anti-Submarine Warfare Range (SOAR) and is important habitat for Ziphius (Falcone et al. 2009). Z. cavirostris is larger than $M$. densirostris (5-7 m long, $1600 \mathrm{~kg}$, and
4.4-4.6 m long, $250 \mathrm{~kg}$, respectively). The foraging habitat metric from Southall et al. (2019) was normalized to the body size of both predator and observed potential prey, facilitating comparison across contexts. In addition to differences in beaked whale species across study sites, the habitats of the 2 regions are quite different. Low nutrient, low productivity, sub-tropical waters surround The Bahamas, while the temperate waters of the California current are strongly influenced by coastal upwelling and are highly productive. The diversity of these data allowed us to use the data sets together to develop a generalized empirical relationship between a key environmental metric, prey availability, and habitat use by deep-diving beaked whales. The functional form of this relationship can reveal much about the processes controlling beaked whale populations and is important for informing ongoing management of these species.

\subsection{Field site}

The Tongue of the Ocean (TOTO) in The Bahamas is a submarine canyon approximately $30 \mathrm{~km}$ wide by $200 \mathrm{~km}$ long that forms the southern branch of the Great Bahamas Canyon (Fig. 1). TOTO exceeds $2000 \mathrm{~m}$ depth in some locations but, with the exception of its northern end, is separated from the open ocean by numerous islands, reefs, and shallow $(<10 \mathrm{~m})$ carbonate banks. The US Navy's AUTEC, a deep-water test and training facility that includes an extensive array of cabled hydrophones, is located in the TOTO. Animals in this area are repeatedly exposed to high levels of military activities, including sonar, which has been shown elsewhere to result in unusual mass strandings (e.g. Fernández et al. 2005, Cox et al. 2006), and more frequent disruptions that may reduce the fitness of the population (Claridge 2013, Moretti 2019). Long-term hydrophone recordings (McCarthy et al. 2011, Tyack et al. 2011 Naval Undersea Warfare Center unpubl. data) at AUTEC have revealed spatial variability in foraging effort, with more foraging animals on the western side of the range than the eastern. Based on these observations, echosounder and other mobile sampling was blocked by these zones within the instrumented portion of the range (Fig. 1, darker gray regions). Previous efforts in these areas suggested that there were also biological differences in fish and invertebrates in the upper water column between these 2 zones (Hazen et al. 2011). Two additional, similarly sized zones were sampled in areas adjacent to the north 


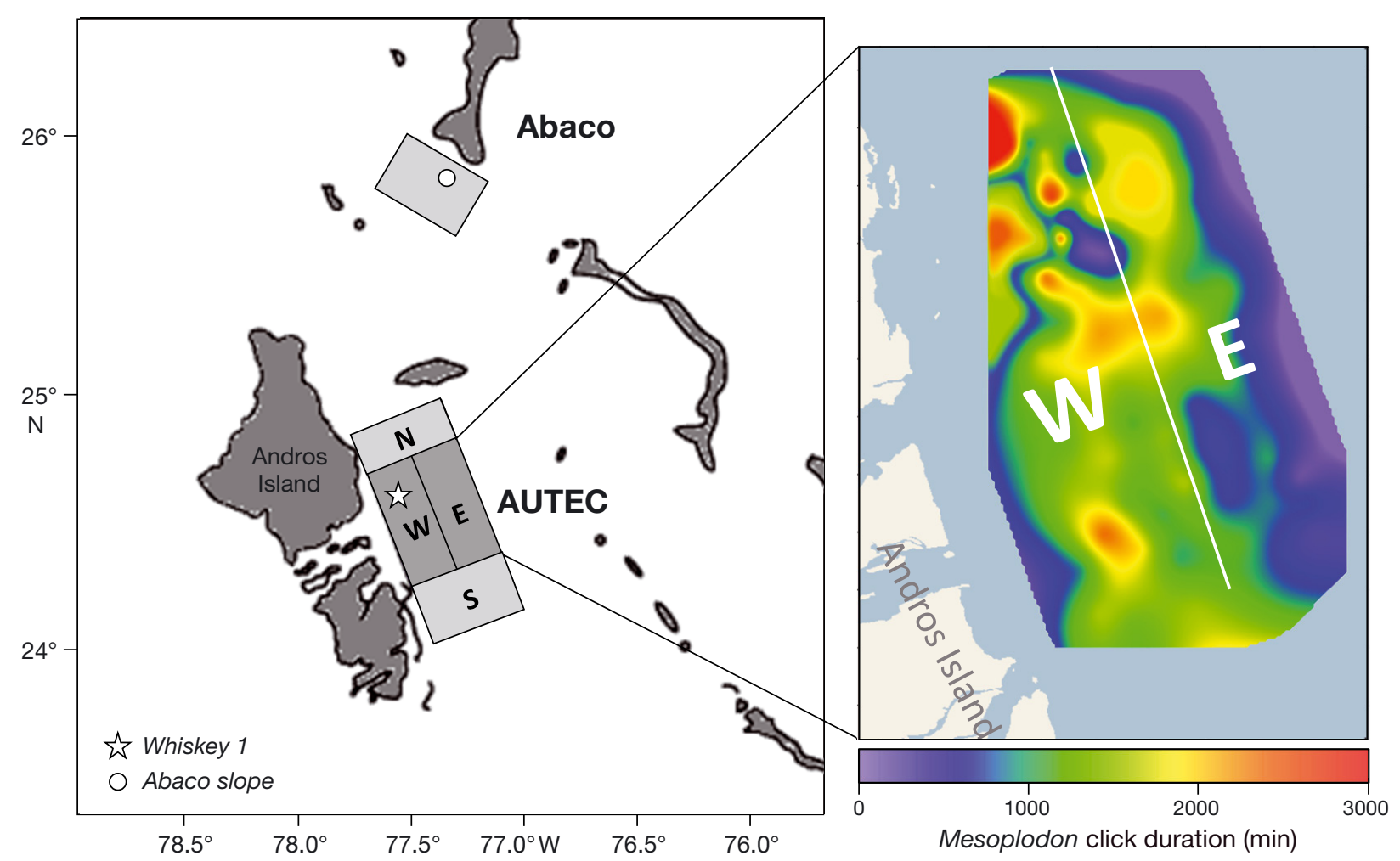

Fig. 1. Sampling locations in The Bahamas, blocked into 5 similarly sized $\left(\sim 500 \mathrm{~km}^{2}\right)$ zones: 2 on the instrumented portion of the US Navy's Atlantic Undersea Test and Evaluation Center (AUTEC) range off Andros Island (W: West; E: East, shown in dark gray), 2 areas adjacent to the range to its North (N) and South (S), and one at the nearby deep-water habitat adjacent to Abaco Island. Prey data were collected using ship-based echosounders and a deep-diving autonomous underwater vehicle along eight $20 \mathrm{~km}$ long transects within each of the zones. In color is the total duration of Mesoplodon densirostris clicks detected by hydrophones on the range in July of 2015. As shown in previous sampling, the species' foraging effort was higher on the western part of the range than the eastern part

and south of the active range, as these areas are likely used by animals as a refuge during navy sonar exercises (McCarthy et al. 2011, Tyack et al. 2011, Joyce et al. 2019). Data from these 4 zones were compared with a region approximately $170 \mathrm{~km}$ north of the range, on the southwest of Great Abaco Island. That area is unlikely to be disturbed by sonar and has a higher proportion of juvenile Mesoplodon than AUTEC (Claridge 2013). Abaco has been used to generate demographic rates for the Mesoplodon in the region (Claridge 2013) (Fleishman et al. 2016, Moretti 2019) and as a comparative site to assess the effects of sonar disturbance on the AUTEC population (Fleishman et al. 2016, Moretti 2019), the metric of management mandated by the Marine Mammal Protection Act (1972).

To investigate whether historical Mesoplodon spatial distributions used to design the sampling were similar to the survey period, AUTEC hydrophones were monitored for echolocation signals during the month in which prey sampling was conducted
(Moretti et al. 2010, McCarthy et al. 2011, Jarvis et al. 2014). The $1500 \mathrm{~km}^{2}$ monitored portion of the range (shaded in dark grey in Fig. 1) consists of 79 hydrophones separated by $\sim 4 \mathrm{~km}$ and two 7 hydrophone hexagonal arrays with a baseline of $1.5 \mathrm{~km}$ (known as Whisky arrays; Whisky 1 is indicated by a star in Fig. 1). Based on the hydrophone characteristics and Mesoplodon signals, any echolocating individual will most likely be detected on at least one hydrophone (DiMarzio et al. 2008, Moretti et al. 2014).

\subsection{Field sampling}

During 2-14 July 2015, 8 transects (20 km long) were sampled during the daytime in each of these 5 zones using a surface vessel and an AUV (Sato \& Benoit-Bird 2017). Two regions known for relatively high habitat use by beaked whales were sampled at a finer spatial scale, using an expanding box with a maximum dimension of $1.5 \mathrm{~km}$ on a side (Moline \& 
Benoit-Bird 2016): an area surrounding Whiskey 1 and the Abaco slope (Claridge 2013). At each of these locations, measurements of the distribution and density of animals in the upper $600 \mathrm{~m}$ of the water column were made using multifrequency $(38,70$, 120, $200 \mathrm{kHz}$ Simrad EK60s) hydro-acoustics from the R/V 'Sharp', which also conducted net sampling for zooplankton and mesopelagic fishes and vertical CTD plus fluorometer profiles to $600 \mathrm{~m}$. Discussed in detail in Sato \& Benoit-Bird (2017), these measurements provide environmental context for comparisons between the study regions. An autonomous echosounder system (38 and $120 \mathrm{kHz}$ Simrad EK60s) integrated into a $600 \mathrm{~m}$ depth-capable AUV (Moline et al. 2015) was used to measure the distribution and density of squid and other resources from 600-1200 m, covering much of the depth range over which beaked whales forage (Johnson et al. 2008). Between 2 and 4 pseudo-randomly chosen transects were sampled with both platforms in concert each day to minimize the effects of time within the survey period while optimizing the use of sampling time.

\subsection{Data analysis}

We utilized methods and selected squid metrics from Benoit-Bird et al. (2016) to summarize the acoustic data from both platforms. Acoustic data analysis was conducted using a combination of Echoview 10.0 and custom LabView routines while statistical analyses were conducted in SPSS Statistics 24 (IBM). Metrics included an integrated biomass proxy (integrated $38 \mathrm{kHz}$ scattering); the number of separable individuals; the proportion of these individuals consistent with squid; the ratio of fishes to crustaceans; estimates of individual size (target strength) by taxonomic class; total energy content per individual squid; the depth of highest squid density (peak depth); and distributional heterogeneity of squid targets measured as relative variance, the density of squid aggregations, and the modal density of individuals within these patches. It is important to recognize that conversion of acoustic proxies to biological parameters always involves simplifications and assumptions. Estimation of target length, for example, assumes that all of the animals with a similar frequency response have the same target strength-to-length relationship, an assumption that is largely correct for animals with similar morphological characteristics but is affected by material properties of animals that can vary between species (McClatchie et al. 2003), introducing potential errors if relative species composition varies across units of comparison. However, within fluid-like scatterers, such as squid, those that have a stronger acoustic contrast with seawater and, as a result, higher target strength values, also generally have higher energy densities. Thus the conversion of target strength to caloric content is fairly robust across squid species (Benoit-Bird \& Au 2002). See a further discussion and sensitivity analysis in Southall et al. (2019). These variables and proxies were calculated for a number of fixed depth ranges $(10-1200,10-600,600-1200$, $10-300,300-600,600-900,900-1200 \mathrm{~m}$ ) including some driven by knowledge of beaked whale foraging (650-1050, 850-1050, 900-1000 m; Johnson et al. 2004, 2008, Baird et al. 2006) at a range of horizontal scales $(10 \mathrm{~km}, 1000 \mathrm{~m}, 100 \mathrm{~m}, 10 \mathrm{~m})$. We also calculated the variability in these parameters with depth in $50 \mathrm{~m}$ depth bins.

MANOVA was used to examine the effect of sampling zone on the metrics of prey resources. Levene's test for equality of variances and Shapiro-Wilk's (SW) test of normality to determine if the data conformed to the assumptions of ANOVA. Tukey's HSD post hoc tests were used to examine which zones accounted for significant effects. Discriminant function analysis was used to further explore the relationships between prey variables and sampling zone. To examine the differences in mean estimated squid length among major habitats (TOTO and Abaco), an ANOVA was used after Levene's and SW tests.

AUTEC hydrophones were monitored for echolocation signals during the month prey sampling was conducted to investigate the spatial distributions of Mesoplodon. Following Southall et al. (2019), clicks recorded on the AUTEC range hydrophones were detected using a custom classifier for each dive. The hydrophone with the largest number of clicks was designated the central hydrophone for that detection to provide a geolocation of the beaked whale group, and the group vocal period (time from the first click for that group to the last) was determined. Group vocal period is a proxy for foraging rather than simple searching (Moretti et al. 2010).

Our study was not designed to explicitly test the effects of our surveys on beaked whale behavior. It did not include a controlled exposure nor high resolution measurements of individual behavior. However, we did evaluate potential responses to our survey operations in a general sense. We compared Mesoplodon group vocal period on the range during, prior to, and after the survey by breaking the range into 4 quadrants and testing the effect of time period relative to the study on the vocal period using an 
ANOVA blocked by these quadrants, following Levene's and SW tests to validate conformation to the assumptions of ANOVA. To further examine the possibility of effects on animal distributions of our presence on the range, we evaluated the spatial distribution of the acoustic detections of Mesoplodon relative to the location of the survey. As the ship and AUV were closer to one another throughout the study than the $4 \mathrm{~km}$ spacing between hydrophones, we used the ship's position in estimating the distance from the central hydrophone for each Mesoplodon detection to our sampling. If the ship's position and the animals' position were random, the convolution of the 2 would result in a Rayleigh distribution, also described as a Weibull distribution with a shape parameter of 2 (Grinstead \& Snell 1997). A KolmogorovSmirnov test was used to compare the distribution of distance between the ship and each beaked whale signal against the predicted Rayleigh distribution for all time periods and for just the periods the AUV was deployed. A quartile-quartile plot of the observed versus expected distribution was examined to identify any specific scales of effects.

To examine the effects of the multiple prey characteristics on beaked whale potential energetic gains, we followed Southall et al. (2019), integrating these metrics with available behavioral and energetic data to develop a simple, relativistic comparative assessment of foraging habitat quality. This foraging habitat quality metric provides a simple yet quantitative means of evaluating the fitness implications of spatial prey heterogeneity and the potential for associated consequences of disturbance to beaked whales across variable ecological contexts. Foraging habitat quality was compared across sampling zones as well as at the finer scale areas known for consistently high beaked whale activity. Importantly, the metric is also scaled to average whale body size so it also allows comparison with data collected and analyzed similarly for the much larger Ziphius off Southern California (BenoitBird et al. 2016, Southall et al. 2019). To facilitate comparisons, a qualitative relative habitat use score was developed for each sampling zone using a combination of available data including passive acoustic estimates of foraging activity during and prior to our study and previously published visual survey data. A value of 1.0 was assigned to the highest use zone on each naval range, with other zones given a habitat use value scaled as a fraction of that value. For example, at AUTEC where acoustically detected animal foraging rates were 2.5 times higher on the highestuse, western part of the range than the eastern part of the range, the eastern site had a habitat use score of
0.4 while the western had a score of 1.0 . We used regression analysis to determine the best functional relationship between the metrics of prey quality and habitat use from among linear, logarithmic, inverse, cubic, power, quadratic, logistic, exponential, and growth. The regression model with the best adjusted value of fit was retained.

\section{RESULTS}

\subsection{The Bahamas}

\subsubsection{Beaked whales}

Hydrophones on the AUTEC range were monitored for beaked whale foraging sounds in the month-long period around our surveys. As the result of a confluence of unusual events, no testing or training exercises were conducted at AUTEC during this time period, limiting the animals' exposure to anthropogenic noise sources including mid-frequency active sonar. The spatial pattern of habitat used by foraging Mesoplodon during July 2015 was similar to earlier observations of habitat use (Hazen et al. 2011). An average of 2.5 times higher foraging effort (quantified as total duration of echolocation clicks) occurred in western versus eastern AUTEC range areas (Fig. 1). These differences were not as stark as those observed in foraging Ziphius at the SOAR range off southern California, where a 10 fold difference was observed between regions of the range at similar spatial scales (Southall et al. 2019).

In evaluating potential behavioral responses to active sonar during the survey, it is noteworthy that the general distribution of vocalizing whales was not different from historical observations nor did it differ between survey and non-survey periods. ANOVA showed a significant effect of the block of sampling zone $(F=181.4, \mathrm{df}=3, \mathrm{p}<0.01)$ but no significant effect of time period relative to the survey $(F=1.06$, $\mathrm{df}=2, \mathrm{p}>0.05$ ). Data did not violate the normality and homogeneity of variance assumptions of ANOVA $(\mathrm{SW}=0.91, \mathrm{p}=0.79$; Levene's $F=0.8, \mathrm{p}=0.61)$ This suggests that beaked whales generally remained in similar areas and continued to forage in similar ways prior to, during, and after the survey period. At a smaller scale, we examined the distance between the center hydrophone and the ship for detections of Mesoplodon on the range. Using Kolmogorov-Smirnov tests, we found that the observed distribution of distances was not different from the expected Weibull distribution for the entire survey 
( $D=0.84, \mathrm{p}>0.20, \mathrm{n}=509$ detections $)$ nor for just the time periods when the AUV was deployed $(D=0.73, \mathrm{p}>0.20$, $\mathrm{n}=289$ ). Based on the quartile-quartile plot of the observed versus expected distances, the data fell quite close to the 1:1 line for both data sets, and there were no obvious drop downs in the line at any scale as we might expect if animals were actively avoiding the ship at some ranges. There was a small degree of mismatch at the tail ends of the distribution where there were very few data points. These results are consistent with observations of Ziphius response off Southern California to the same systems and similar survey design (Southall et al. 2019) and a similar survey using a multibeam echosounder (Kates Varghese et al. 2020), though in other locations beaked whales have been observed to respond to echosounders at finer scales than were possible to observe here (Cholewiak et al. 2017). Here, habitat used by the whales matched the historical observations that guided the sampling design and did not have a spatially variable response to the sampling. The strong fit of the distances between beaked whales and the ship to the expected distribution provides support for the interpretation of spatial patterns in whales and resources during the time of sampling.

\subsubsection{Potential beaked whale prey}

Acoustic samples of potential beaked whale prey in The Bahamas were collected in 5 zones: a relatively higher use habitat on the western part of the range, a lower use area on the eastern part of the range, south of the range, north of the range, and a less-disturbed comparison site off the range near Great Abaco Island. Results from the MANOVA showed a significant effect of sampling zone on prey metrics (Table 1; $F=15.36, \mathrm{df}=24,36.1, \mathrm{p}<0.001$, where data did not violate the ANOVA assumptions of homogeneity [Levene's $F=0.69, \mathrm{p}=0.61$ ] or normality [SW $=0.71, \mathrm{p}=0.75]$ ). Tests of the betweensubjects' effects of sampling zone were significant for all dependent variables ( $\mathrm{df}=4, \mathrm{p}<0.05$ for all comparisons) with the exception of the ratio of fish to crustacean targets $(F=0.32, \mathrm{df}=4, \mathrm{p}>0.1)$. Tukey's HSD post hoc tests showed that all zones were significantly different from each other for these dependent variables $(\mathrm{p}<0.05$ for all comparisons)
To determine which dependent variables and combinations of variables were important in separating zones, we used discriminant function analysis. Sampling zones were generally well separated (Fig. 2) by 2 discriminant functions which accounted for $95.3 \%$ of the variance observed at the transect level. The

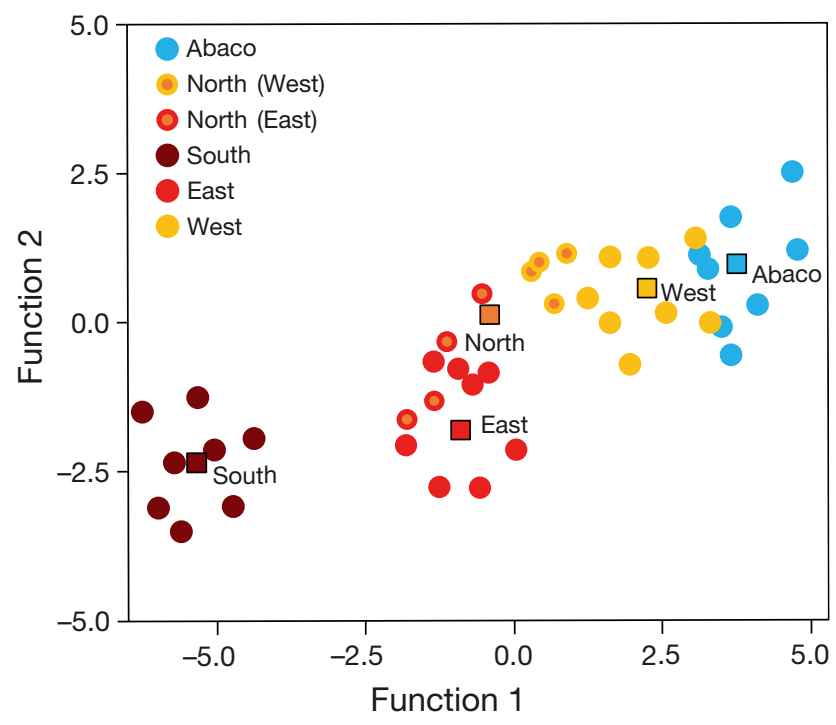

Fig. 2. Discriminant analysis plot of the first 2 discriminant functions representing $95.3 \%$ of the variance in prey measures observed between the 5 zones in Fig. 1. Dots: function values for individual transects with each zone in a different color; squares: centroid for each zone. Patterns in both discriminant functions were consistent with our understanding of the relative use of the habitat by Mesoplodon, with higher values of each function for zones with greater habitat use. Only the North habitat was not well separated from other sampling zones; transects on the east side of the North zone (orange dots outlined in red) were in the same reduced variable space as those from the eastern range while those on the west side of the North zone (orange dots outlined in yellow) were close to the western transects in variable space 
North Zone was not well separated from the zones on the instrumented part of the AUTEC range; transects on the east side of the North Zone were in the same reduced variable space as those from AUTEC East, while those on the west side of the North Zone were close to AUTEC West transects in variable space. Because of this spatial variation, foraging habitat quality was not estimated for the North Zone.

Patterns in both discriminant functions (Fig. 2) were consistent with our understanding of the relative use of the habitat by Mesoplodon, with higher values of each function for zones with greater habitat use. Based on foraging click activity, the least used habitat on the instrumented range, AUTEC East, is near the lower left while the most used zone on the instrumented range, AUTEC West, is near the upper right. Abaco, which has more favorable population demographic characteristics compared to AUTEC, is on the upper right of the plot. Function 1, explaining $78.5 \%$ of the variance, consisted of the variables (in descending order of influence) mode squid spacing
(900-1000 m), peak squid depth, $100 \mathrm{~m}$ scale patchiness of squid targets (850-1050 m), and focal prey proportion (900-1200 m). Function 2, explaining $16.8 \%$ of the variance, included maximum density of squid targets (850-1050 m), mean squid target strength (600-1200 m), and $100 \mathrm{~m}$ scale variability over depth (600-1200 m).

There were differences across zones in coherence between the upper water column and the depths at which beaked whales forage (Fig. 3). For example, in the upper $600 \mathrm{~m}$ of the water column, we found higher total acoustic scattering at $38 \mathrm{kHz}$ on the eastern side of the AUTEC range than the west, while the opposite pattern was observed at depths between 900 and $1200 \mathrm{~m}$. This is in contrast to previous work that found higher scattering in the upper water column on the west side of the range (Hazen et al. 2011) but is similar to the incoherence between the surface ocean and the deep observed off Southern California (Benoit-Bird et al. 2016). In contrast, we observed coherence between acoustic scattering in the upper

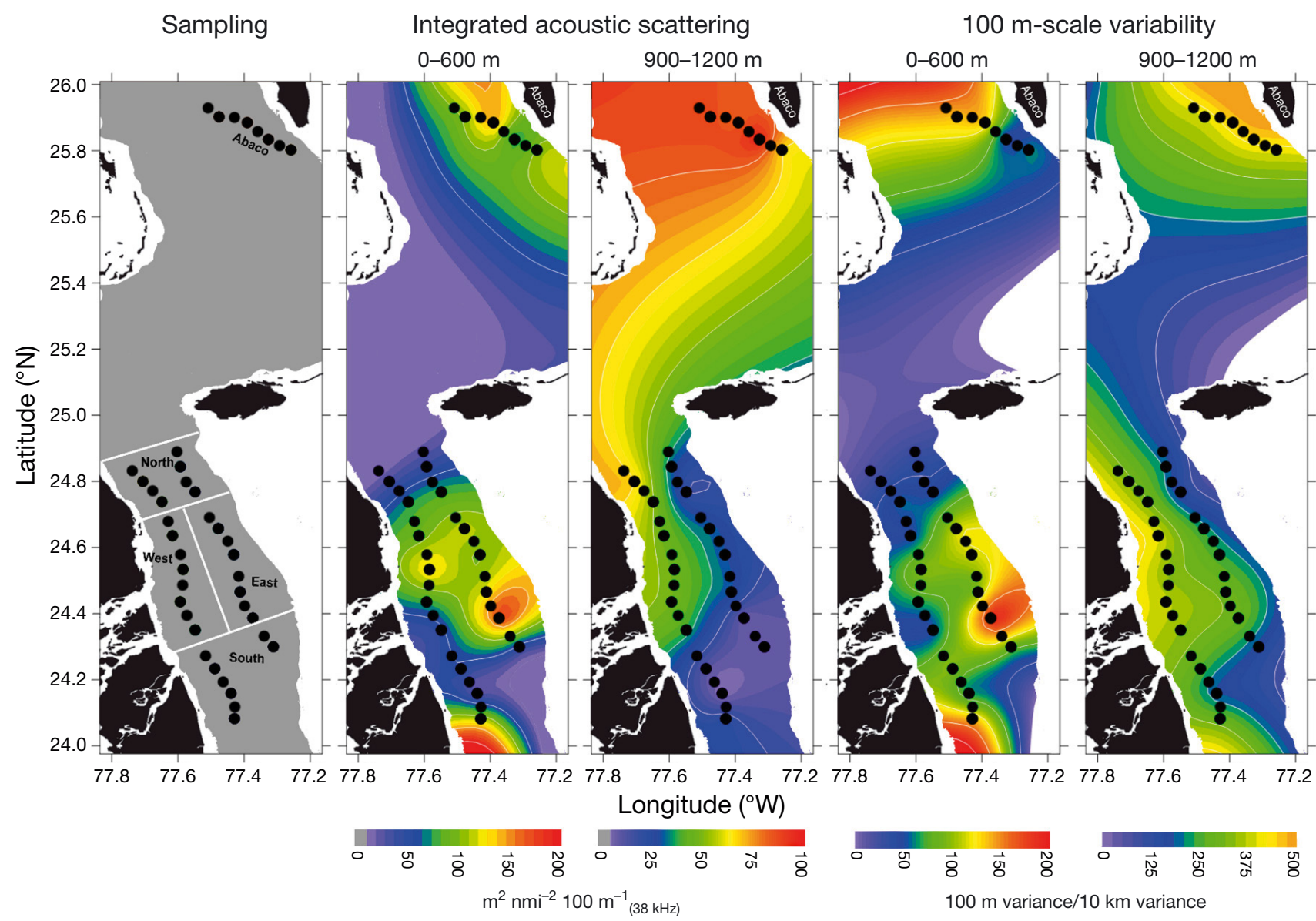

Fig. 3. Distribution of potential prey in the upper water column compared to the depths over which Mesoplodon are most likely to forage. Black dots: center of each sampling transect. Map surfaces were generated using minimum curvature interpolations. Note the differences in scale bars between panels 
and lower water column in some locations, like the South Zone, where acoustic scattering was relatively low throughout the water column, and Abaco where the highest integrated scattering measures of any zone were observed from the surface to $1200 \mathrm{~m}$, particularly in the northern transects. Measures of spatial variability at $100 \mathrm{~m}$ scales showed similar incoherence between surface waters and the depths where beaked whales forage (Fig. 3).

Throughout the food chain, biotic features were deeper at Abaco than in the TOTO sites, beginning with the subsurface chlorophyll max, including mesopelagic scattering layers as well as the peak depth of larger animals consistent with squid (Fig. 4). Across these biotic features, there were no substantial differences in the levels or integrated proxies of biomass between the 2 sites. However, deep-water acoustic targets identified as squids (ANOVA: $F=3.49, \mathrm{df}=1,19, \mathrm{p}<0.05$ ) and those identified as fishes (ANOVA: $F=2.81$, df $=1,19$, $\mathrm{p}<0.05$ ) were significantly larger (ANOVA: $F=$ 3.49 , df $=1,19, \mathrm{p}<0.05)$ at Abaco than the TOTO sites and between AUTEC West and Abaco (Tukey's HSD: Squid: mean difference $=1.02 \mathrm{~cm}, 95 \% \mathrm{CI}=$ $0.74-1.78 \mathrm{~cm}, \mathrm{p}<0.05$; Fishes: mean difference $=$ $1.22 \mathrm{~cm}, 95 \% \mathrm{CI}=0.51-2.08 \mathrm{~cm}, \mathrm{p}<0.05)$. All

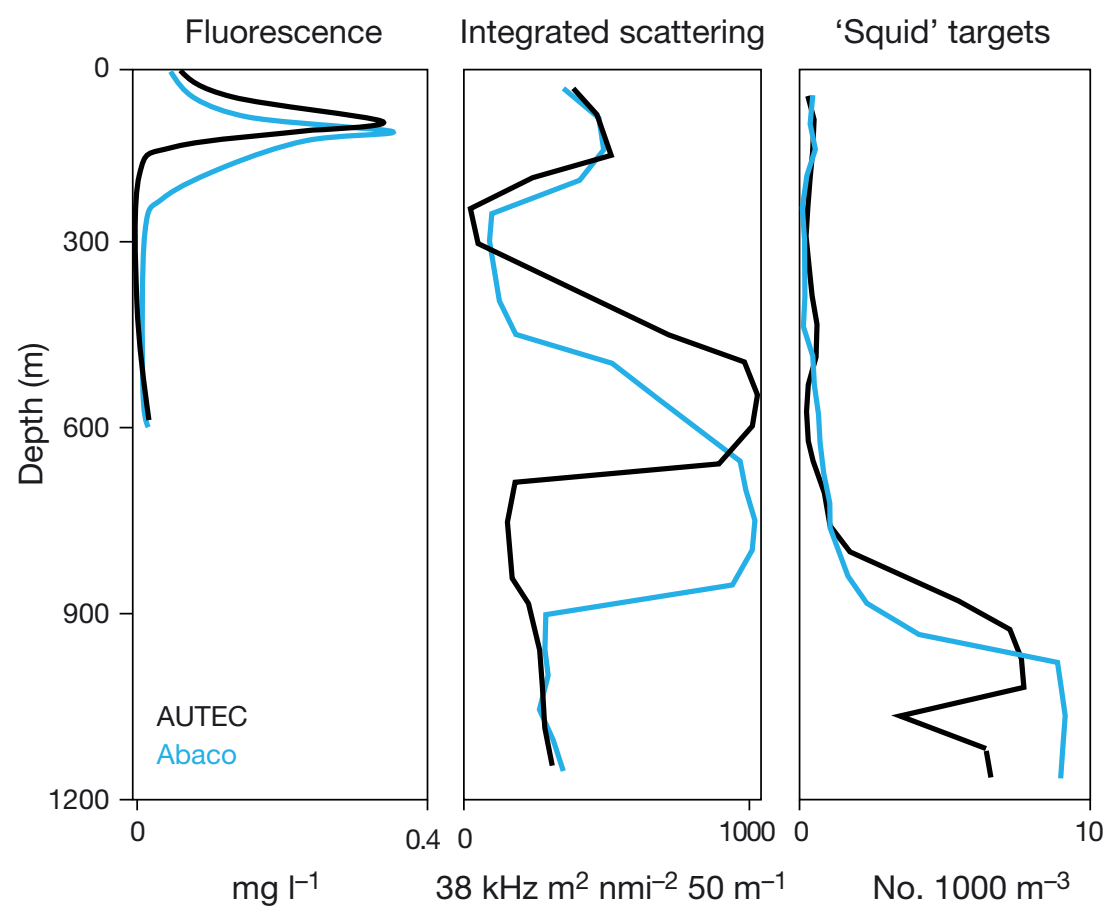

Fig. 4. Throughout the food chain, biotic features were deeper at Abaco than the AUTEC sites, beginning with the subsurface chlorophyll max (left), including mesopelagic scattering layers (center) as well as the peak depth of larger animals consistent with squid (right) data met the homogeneity and normality assumptions of ANOVA (SW, p > 0.25; Levene's, p > 0.18 for all comparisons)

\subsection{Comparative results}

To examine the collective effects of prey variables on potential Mesoplodon foraging gains, we utilized an integrated foraging habitat quality metric. This metric is in units of dives per day that an individual beaked whale would need to meet its basic energy needs if it could consume every squid it encountered. While simplistic, this relativistic measure incorporates multiple prey variables with the biology and behavior of the predator, allowing us to compare across zones and habitats. Importantly, the metric is scaled to average body size so it also allows comparisons between species. The relative Mesoplodon foraging habitat quality metrics for The Bahamas sites are shown in Fig. 5. Data presented in Southall et al. (2019) for Ziphius in Southern California are also shown. The relative ordering of the zones in The Bahamas corresponds with the pattern of zones identified by discriminant function analysis in Fig. 2. The ordering at both The Bahamas and California sites generally corresponds with observations of relative habitat use by beaked whales across these zones, with areas of highest use requiring the fewest dives for an individual beaked whale to access resources, while areas of low use would require many more dives per day than these animals can undertake based on their physiological constraints. Finer scale sampling regions at AUTEC and Abaco in areas known to have consistently high beaked whale foraging showed these areas would have required the fewest dives per day for beaked whale prey acquisition during our sampling period.

Differences in habitat use in passive acoustic and visual survey data were quantified using a scoring system where relative habitat use is referenced to the highest use zone on each naval range. These scores are plotted as a function of the prey quality metric in dives per day in Fig. $6\left(F_{1,6}=1724.47\right.$, $\mathrm{p}<0.001$, adjusted $\mathrm{R}^{2}=0.99$ ). There was a consistent power function relationship between these variables across 
Foraging habitat quality metric (est. dives required $\mathrm{d}^{-1}$ )

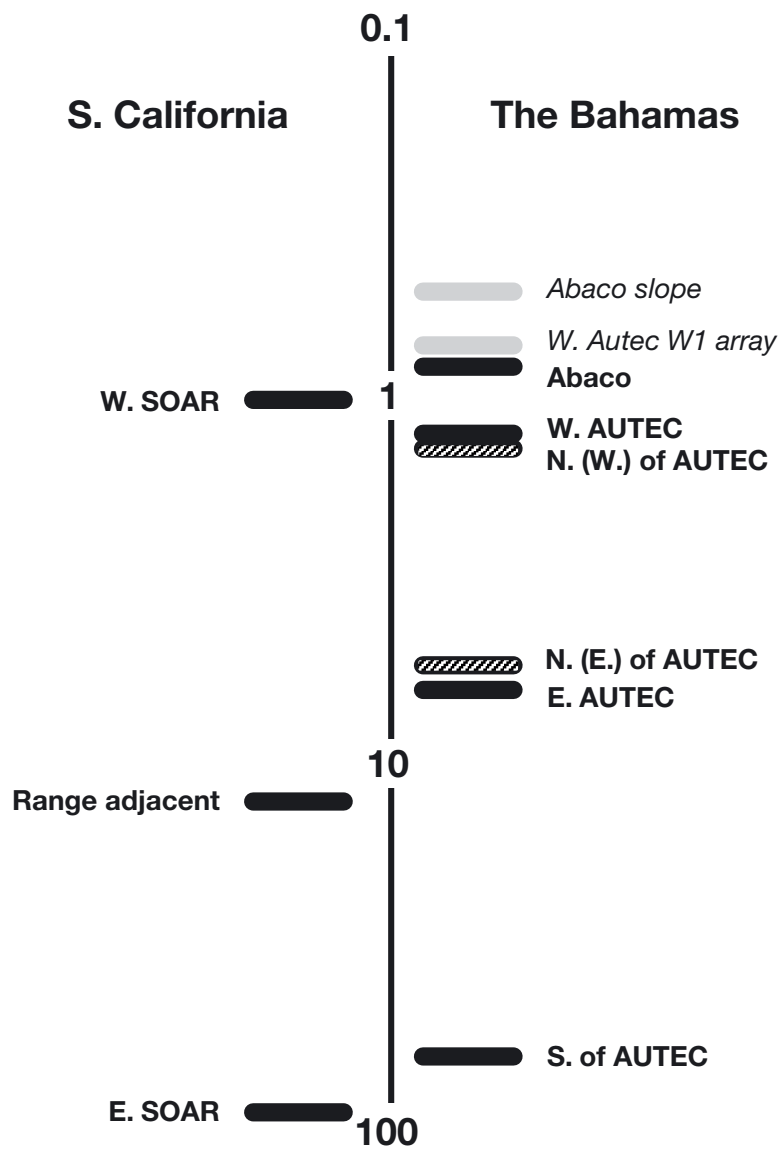

Fig. 5. Prey data were combined into a relativistic measure of Mesoplodon foraging habitat quality that incorporates multiple prey variables with the biology, behavior, and size of the predator to allow comparison across zones, habitats, and species (Southall et al. 2019). Each sampling zone is shown in black, for Southern California and The Bahamas. The North zone in The Bahamas is split into east and west parts, shown in dashed lines. Finer scale sampling at known beaked whale hotspots in The Bahamas is shown in grey. The high-use habitats in each location have prey quality metrics of approximately 1 dive $\mathrm{d}^{-1}$ or around $10 \%$ of the observed daily dive rate for beaked whales. SOAR: Southern California Anti-Submarine Warfare Range; W1: Whiskey 1. See Fig. 1 for locations in the Bahamas

sites and zones, with habitat use best predicted by one over the square root of the foraging habitat quality metric. A power distribution is scale-free, meaning that as we change the units by which we measure environmental quality, the shape of the distribution is unchanged except for an overall multiplicative constant, making our precise means of quantifying environmental quality and habitat use less important than their relative scaling. However, because of the small number of data points, the specific details of the numerical relationship must be extrapolated with care.

\section{DISCUSSION}

The distribution of potential prey plays a critical role in driving the observed distribution of beaked whales and explaining the persistent use of US Navy ranges by beaked whales despite repeated disturbance from many human noise sources, including powerful active sonar systems associated with whale strandings. Understanding the distribution of prey and how it relates to patterns of whale distribution and disturbance plays a vital role in determining the energetic and potential population costs of these range activities for population management. The list of important potential prey variables separating these zones does not include the estimated biomass of resources. Instead, these variables separating sampling zones describe the spatial organization of squid, similar to findings from other beaked whales off Southern California (Southall et al. 2019) as well as in other predator-prey systems (Benoit-Bird et al. 2013). As off Southern California, beaked whales in The Bahamas also preferentially used habitats with larger individual squid that likely have greater energy content and those where squid made up a greater proportion of potential prey targets. Both of these factors potentially reduce search and handling costs (Warburton \& Thomson 2006) by increasing the signal-to-noise ratio in biosonar echoes while reducing the need to process acoustic information from non-target prey and make decisions about whether and when to pursue prey as well as reducing the chance of prey targeting errors.

Our prey analyses focused on the characteristics of targets consistent with squid because of the primarily teuthivorous diet described for beaked whales. However, species in the genus Mesoplodon consume fish in some locations (Clarke 1996, MacLeod et al. 2003). A variety of recent evidence, including stable isotope analysis, fecal samples, and gut contents, suggests that Mesoplodon in The Bahamas include fishes in their diet as well (D. E. Claridge et al. unpubl. data), though the relative importance of fishes in their overall energy budget is not clear. The relative proportion of squid between 600-1200 m varied significantly between zones. However, at beaked whale foraging depths, the ratio of targets consistent with crustaceans to those consistent with fishes did not vary significantly across zones, averaging 2.1 crustaceans: 1 fish. Thus, the South Zone, with only $9 \%$ squid targets had a greater proportion of fishes than Abaco, which had $37 \%$ squid. Differences in the density of targets between these sites meant the total 


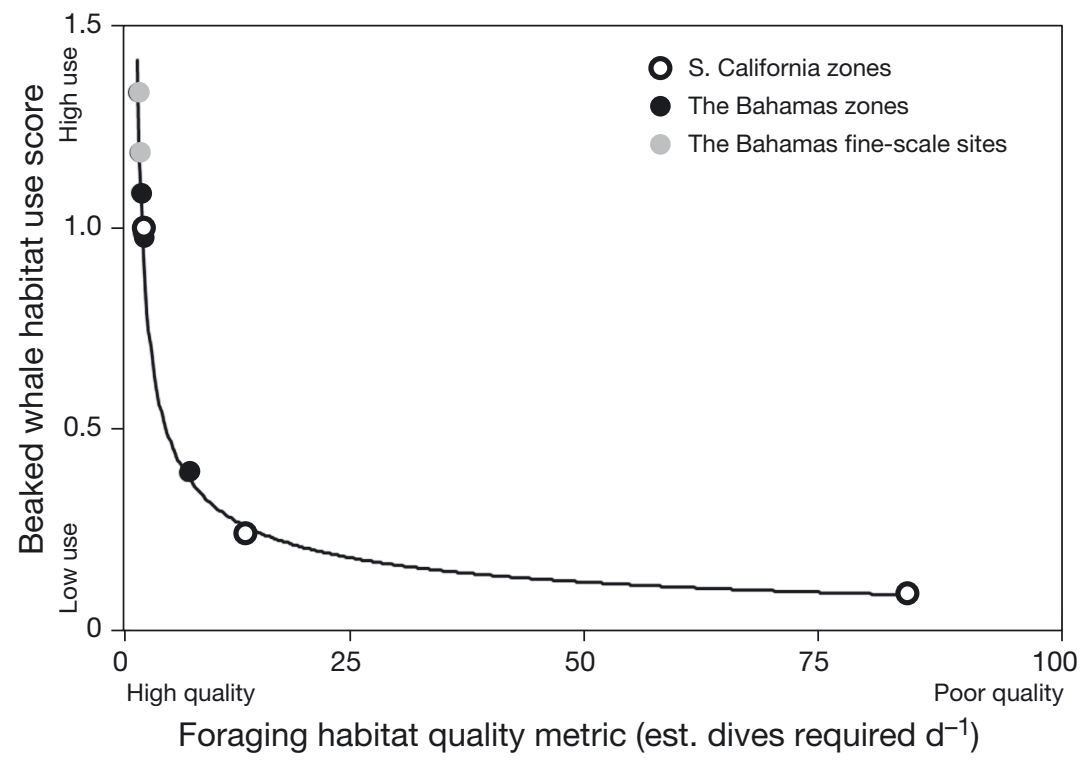

Fig. 6. Habitat use by beaked whales for each sampling unit scored relative to the highest use site on each Navy range using a combination of available passive acoustic and visual survey data. These scores $(\mathrm{N}=8)$ are shown as a function of the foraging habitat quality metric developed by Southall et al. (2019) using prey data collected in the same areas. Not included are the North and South zones adjacent to AUTEC as not enough data on beaked whale distributions exists to establish a habitat use score. The best-fit regression, a power relationship, is shown as a solid line. Data for Southern California from BenoitBird et al. (2016)

number of fish targets was similar across all locations during the study. The target strength of each taxonomic class was significantly higher at Abaco than at the TOTO sites.

All of the prey variables statistically separating zones defined a priori by Mesoplodon activity include depth ranges overlapping with the peak depths of foraging buzzes between 650 and $1050 \mathrm{~m}$ observed in this area (L. S. Hickmott et al. unpubl. data) and in this species in other areas (Johnson et al. 2004, 2008). The differences between zones we observed at these depths were, however, not always evident in the upper water column, as we observed differences in coherence between the upper and deep column across the study area with low scattering in the portion of the range most used by beaked whales. This is in contrast to previous work that found higher scattering in the upper water column on the western, high-use side of the range (Hazen et al. 2011) but is similar to the incoherence between the surface ocean and the deep observed off Southern California (Benoit-Bird et al. 2016). In contrast, we observed coherence between acoustic scattering in the upper and lower water column in some locations, such as the South Zone where acoustic scattering was relatively low throughout the water column, and Abaco where the highest integrated scattering measures of any zone were observed from the surface to $1200 \mathrm{~m}$. Measures of spatial variability at $100 \mathrm{~m}$ scales showed similar incoherence between surface waters and the depths where beaked whales forage (Fig. 3). These observations confirm the conclusion that for deepdiving predators, surface-based sampling to predict prey resources can lead to inappropriate conclusions when the mechanisms and time scales of connection between surface and the deep are not well known. In the ecosystems that are critical habitat for beaked whales, such as most pelagic systems, large-scale, long-term, controlled manipulations are difficult. Instead, pseudo-experimental analyses that treat independent beaked whale populations as 'replicates' and spatial contrasts in disturbance as 'treatments' are used to disentangle the effects of disturbance like sonar from natural variation and statistical noise on populations. One such comparison has been the AUTEC range, where human disturbance is a regular feature of the environment, and the area around Great Abaco Island, where disturbance by military sonars is comparatively infrequent (Moretti 2019). Despite their close proximity (170 km separates the 2 sites), the home ranges of animals in these 2 areas do not appear to overlap (Claridge 2013). The average annual abundance of animals at AUTEC West and calf-to-female ratios are significantly lower than at Abaco, leading to the suggestion that military activities at AUTEC have led to negative population consequences to Mesoplodon on the range (Claridge 2013, Moretti 2019). Comparisons between locations can provide a powerful tool for revealing the processes driving populations. We observed that the zones most used by beaked whales at both sites share a number of prey features at the depths over which beaked whales forage, including relatively high proportions of larger squid distributed in aggregations. These same features were observed to correlate with beaked whale habitat use off Southern California (Southall et al. 2019), revealing much about what prey features are important for beaked whale success. In terms of the distribution of deepwater squid, AUTEC West was more similar to Abaco than it was to the contiguous area, AUTEC East. The 
differences within AUTEC have been proposed to be driven by localized upwelling, the location of steep topography, and the strength of the thermocline (Hazen et al. 2011).

Despite the general similarities in prey characteristics in Mesoplodon foraging habitat, our results highlight substantial differences in resources during our study between even the parts of the AUTEC range most used by Mesoplodon and the Abaco site. Squid measurements at Abaco were more favorable for beaked whales than those at AUTEC on all measures considered, with higher overall densities of squid that are larger, more closely spaced, and make up a larger proportion of potential acoustic targets. These differences are less pronounced but still statistically significant when comparing only AUTEC West and Abaco. Overall, during the 2 wk timeframe of this study, Abaco appeared to be a more energy efficient ecosystem, with more extensively migrating mesopelagic animals, larger animals from zooplankton to nekton, and a greater degree of vertical overlap amongst trophic steps than TOTO (Sato \& BenoitBird 2017). This resulted in an approximately $20 \%$ difference in foraging habitat quality metrics between similarly sized zones on the parts of the AUTEC range most used by Mesoplodon and Abaco and up to a 20 fold difference from Abaco if the entire TOTO region sampled is considered, though the scale differences in this comparison must be considered. These differences in foraging habitat characteristics should not be surprising given the dramatic differences in oceanography between the 2 sites, with Abaco experiencing conditions consistent with an open-ocean ecosystem, while TOTO is isolated from these oceanic influences, acting as a closed ecosystem from a physical and likely biological perspective. Much more subtle variations in topography and oceanography have been shown to influence the habitat preferences of Mesoplodon in The Bahamas (MacLeod \& Zuur 2005). Our observations of prey resources, while limited in time, combined with these overall differences in habitat characteristics provide an alternative hypothesis to disturbance to account for the differences in beaked whale populations observed between TOTO and Abaco slope. The results presented here highlight the care that must be taken in interpreting pseudo-experimental population contrasts where natural environmental variation cannot be accounted for. Vital rates established for one population should not be considered a baseline for the other without careful consideration of context provided by the habitat, including prey. This study has advanced our ability to interpret demo- graphic differences between AUTEC West and Abaco and will better inform models predicting population consequences of disturbance.

\subsection{Comparative results}

Using a comparative metric of foraging habitat quality that integrates prey variables and normalizes them using knowledge of whale biology lets us combine the results from The Bahamas sites with similarly collected data off Southern California, providing information on the relationship between beaked whales and their deep-water prey more generally. Despite the differences in the size of the species of beaked whale found in the 2 locations and the contrasts in the ecosystems themselves, those zones historically observed to have the greatest rates of foraging by beaked whales had prey quality metrics at or below a value of 1 dive $\mathrm{d}^{-1}$, about $10 \%$ of observed daily dive rates (Southall et al. 2019). This proportion of observed daily dives may perhaps be an even more robust indicator of the potential foraging gains. However, the value of the metric, which is affected by the specifics of the parameterization, is less important than the consistency observed and the shape of the relationship between the metric and habitat use by beaked whales. Determining the form of predatorprey relationships is critical for understanding ecosystem dynamics and managing predator populations relative to the host of threats that they face. For beaked whales, the functional relationship developed with their prey in and near US Navy test ranges shows that small changes in prey can have large consequences for how beaked whales use their habitat. Using this understanding, it is possible to compare locations to determine where whales are likely to spend the most time. For example, based on the data presented here, we hypothesize that Mesoplodon should spend relatively little time foraging in the South zone. Animals that avoid activities on the range by moving to the north should be able to access similar levels of food on the western side of that zone, though concentration of animals or overlap with animals that generally inhabit the northern area could increase competition for these resources. These predictions could be extrapolated to include changes over time as resources change naturally or as a result of climate change. Prey information, integrated with predator information as is done here, could also inform site selection for activities within ranges, the selection of sites for new activities with the goal of minimizing impacts on beaked whale 
populations, or the selection of protected areas (Hooker et al. 2002).

Far from the linear relationship between resources and gains assumed in existing models, our results indicate a critical threshold in prey characteristics for beaked whale foraging success measured as habitat use, below which predators are unlikely to be successful but above which small changes in resources allow large gains to the predator. The power-law functional relationship observed indicates that only a small range of measured habitat quality values is preferred by beaked whales. Responses to threshold levels of prey are commonly observed in oceanic predators (Cury et al. 2011), though the shape typically involves an asymptote above which gains are no longer realized (Holling 1959), a point not observed here.

Our empirical observations are most consistent with the form of a Type III functional response described by Holling (1959). Type III responses occur in predators that increase their search activity with increasing prey density or exhibit dietary switching to the most abundant prey species, which can result in regulation of prey density by a stable population of predators. This observation provides insight into theoretical and mathematical avenues for future examination of beaked whale populations. For example, the shape of the relationship between beaked whales and their resources informs the ongoing development of energetic models aimed at connecting observations of short-term behavioral responses of beaked whales facing disturbance with population-level consequences (New et al. 2013, Hin et al. 2019, Moretti 2019). The appearance of an apparently sharp threshold in the functional relationship between beaked whale habitat preferences and their prey has significant ecological as well as management implications; relatively small behavioral changes resulting from disturbance could have unpredicted yet consequential population effects, including decreased individual growth, reproductive, and other vital rates. An additional consequence is that models of beaked whale populations seeking to incorporate prey will be very sensitive to the parameters chosen, emphasizing the importance of these difficult to obtain and currently rare data.

\subsection{Conclusions}

We observed extensive spatial heterogeneity in foraging habitat at submesoscales $(<100 \mathrm{~km}$; the scale of oceanic eddies and similar interactions between currents and other bodies of water) in both a temperate upwelling and low-productivity subtropical ecosystem. Strong variation in resources over horizontal distances smaller than the potential habitat range of an individual beaked whale suggests that careful direct evaluation of the habitat is needed for siting of human activities within these habitats. Further evaluation of potential differences in prey species composition that cannot currently be addressed with acoustic tools should also be examined at these scales by employing large deep-water trawls, video imaging on robotic platforms, or other techniques.

In The Bahamas, Mesoplodon appear to have much to gain in the western sector of the AUTEC range. While it may be practically infeasible to suggest establishing a sonar-free area in this region given the presence of the expensive, extensive range facility, one potential mitigation action consistent with our results would be to concentrate mid-frequency active sonar (MFAS) operations on the eastern side of the AUTEC range rather than the western, higher-use side when possible. This spatially explicit action could reduce the potential consequences of disturbance in this important habitat for Mesoplodon, at least for those occurring at higher sonar intensities and at the shorter ranges where the greatest behavioral changes have been shown to occur (Falcone et al. 2017). In addition, care should be taken to avoid activities that shepherd animals southward, where prey resources immediately adjacent to the range were observed to be unfavorable for beaked whale foraging. Activities that limit movement of southerly animals to regions to the northwest of the range, where our habitat measures suggest prey were similar to the most used parts of the range, should also be avoided. Incorporation of our results into models evaluating the population consequences of disturbance from Navy MFAS will allow explicit comparisons of the relative energetic consequences of various disturbance scenarios, further enabling decision making about the spatio-temporal dynamics of sonar activities.

Our historical view of the deep sea as unchanging and disconnected from surface-driven processes (Menzies 1965) is being challenged by recent research showing how susceptible these extensive and diverse habitats, particularly the top predators in them, are to threats from fishing, mining, dumping, climate change, and other anthropogenic stressors, including sound (Davies et al. 2007). The unprecedented deep-sea data provided by our combined work within 2 ecologically disparate regions of naval 
importance tells us about these areas, about beaked whale ecology, and the biological and management relevance of spatial heterogeneity of resources. This work also contributes to our changing perspective on the ocean and how we manage it. We are in a race to describe and understand this 'last great wilderness' (Roberts 2002) where there may be 'a million undescribed species, with biological adaptations and ecological mechanisms that we cannot yet imagine' (Robison 2004, p. 253). The empirically derived, functional relationship between beaked whale predators and their deep-dwelling squid prey provides new and surprising insights into the processes affecting ocean predators, the ecological structure and dynamics of the deep-sea ecosystems they inhabit, and the potential effects of human activities on the ecologically and economically valuable habitat that makes up the largest living space on our planet.

Acknowledgements. We thank the crew of the R/V 'Sharp' and staff at the Atlantic Undersea Test and Evaluation Center for field support. Thomas Leo, Nancy DiMarzio, and Stephanie Watwood provided logistical support for the range. Chad Waluk provided technical expertise, assisted with equipment setup and data collection, and conducted pre-processing of the CTD and acoustic data. Marnie Jo Zirbel provided taxonomic expertise. Mei Sato, Ian Robbins, Megan Cimino, and Matthew Breece participated in the field operations. This work was funded by the Office of Naval Research Marine Mammal Biology Program (Grant No.: N00014-15-1-2204). We thank program manager Michael Weise for his assistance coordinating with the Navy and supporting other logistics that made this work possible. This work was conducted under a research permit (No. 12A) issued by The Bahamas Department of Marine Resources as authorized under The Bahamas Marine Mammal Protection Act (2005).

\section{LITERATURE CITED}

Baird RW, Webster DL, McSweeney DJ, Ligon AD, Schorr GS, Barlow J (2006) Diving behaviour of Cuvier's (Ziphius cavirostris) and Blainville's (Mesoplodon densirostris) beaked whales in Hawai'i. Can J Zool 84: $1120-1128$

Benoit-Bird KJ, Au WWL (2002) Energy: converting from acoustic to biological resource units. J Acoust Soc Am 111:2070-2075

* Benoit-Bird KJ, Battaile BC, Heppell SA, Hoover B and others (2013) Prey patch patterns predict habitat use by top marine predators with diverse foraging strategies. PLOS ONE 8:e53348

Benoit-Bird KJ, Southall B, Moline M (2016) Predator guided sampling reveals biotic structure in the bathypelagic. Proc R Soc B 283:20152457

Cholewiak D, DeAngelis AI, Palka D, Corkeron PJ, Van Parijs SM (2017) Beaked whales demonstrate a marked acoustic response to the use of shipboard echosounders. R Soc Open Sci 4:170940
Choy CA, Drazen JC (2013) Plastic for dinner? Observations of frequent debris ingestion by pelagic predatory fishes from the central North Pacific. Mar Ecol Prog Ser 485: $155-163$

Claridge DE (2013) Population ecology of Blainville's beaked whales (Mesoplodon densirostris). PhD dissertation, University of St Andrews

Clarke MR (1996) Cephalopods as prey. III. Cetaceans. Philos Trans R Soc B 351:1053-1065

Cox TM, Ragen T, Read A, Vos E and others (2006) Understanding the impacts of anthropogenic sound on beaked whales. J Cetacean Res Manag 7:177-187

Cury P, Bakun A, Crawford RJ, Jarre A, Quinones RA, Shannon LJ, Verheye HM (2000) Small pelagics in upwelling systems: patterns of interaction and structural changes in 'wasp-waist' ecosystems. ICES J Mar Sci 57:603-618

* Cury PM, Boyd IL, Bonhommeau S, Anker-Nilssen T and others (2011) Global seabird response to forage fish depletion-one-third for the birds. Science 334: 1703-1706

*Davies AJ, Roberts JM, Hall-Spencer J (2007) Preserving deep-sea natural heritage: emerging issues in offshore conservation and management. Biol Conserv 138: 299-312

DiMarzio N, Moretti D, Ward J, Morrissey R and others (2008) Passive acoustic measurement of dive vocal behavior and group size of Blainville's beaked whale (Mesoplodon densirostris) in the Tongue of the Ocean (TOTO). Can Acoust 36:166-172

Falcone EA, Schorr GS, Douglas AB, Calambokidis J and others (2009) Sighting characteristics and photo-identification of Cuvier's beaked whales (Ziphius cavirostris) near San Clemente Island, California: A key area for beaked whales and the military? Mar Biol 156: 2631-2640

Falcone EA, Schorr GS, Watwood SL, DeRuiter SL and others (2017) Diving behaviour of Cuvier's beaked whales exposed to two types of military sonar. R Soc Open Sci 4: 170629

* Fernández A, Edwards J, Rodriguez F, de los Monteros AE and others (2005) 'Gas and fat embolic syndrome' involving a mass stranding of beaked whales (Family Ziphiidae) exposed to anthropogenic sonar signals. Vet Pathol 42:446-457

Ferretti F, Worm B, Britten GL, Heithaus MR, Lotze HK (2010) Patterns and ecosystem consequences of shark declines in the ocean. Ecol Lett 13:1055-1071

Filadelfo R, Mintz J, Michlovich E, D'Amico A, Tyack PL, Ketten DR (2009) Correlating military sonar use with beaked whale mass strandings: What do the historical data show? Aquat Mamm 35:435-444

Fleishman E, Costa DP, Harwood J, Kraus S and others (2016) Monitoring population-level responses of marine mammals to human activities. Mar Mamm Sci 32: 1004-1021

Friedlaender AS, Hazen E, Goldbogen J, Stimpert A, Calambokidis J, Southall B (2016) Prey-mediated behavioral responses of feeding blue whales in controlled sound exposure experiments. Ecol Appl 26:1075-1085

Grinstead CM, Snell JL (1997) Introduction to probability. American Mathematical Society, Providence, RI

Hazen EL, Nowacek DP, Laurent LS, Halpin PN, Moretti DJ (2011) The relationship among oceanography, prey fields, and beaked whale foraging habitat in the Tongue of the Ocean. PLOS ONE 6:e19269 
Hazen EL, Jorgensen S, Rykaczewski RR, Bograd SJ and others (2013) Predicted habitat shifts of Pacific top predators in a changing climate. Nat Clim Chang 3:234-238

Heithaus MR, Frid A, Wirsing AJ, Worm B (2008) Predicting ecological consequences of marine top predator declines. Trends Ecol Evol 23:202-210

Hin V, Harwood J, de Roos AM (2019) Bio-energetic modeling of medium-sized cetaceans shows high sensitivity to disturbance in seasons of low resource supply. Ecol Appl 29:e01903

Holling CS (1959) The components of predation as revealed by a study of small-mammal predation of the European pine sawfly. Can Entomol 91:293-320

*Hooker SK, Whitehead H, Gowans S (2002) Ecosystem consideration in conservation planning: energy demand of foraging bottlenose whales (Hyperoodon ampullatus) in a marine protected area. Biol Conserv 104:51-58

Huntley ME, Lopez MD, Karl DM (1991) Top predators in the Southern Ocean: a major leak in the biological carbon pump. Science 253:64-66

Jarvis SM, Morrissey RP, Moretti DJ, DiMarzio NA, Shaffer JA (2014) Marine Mammal Monitoring on Navy Ranges (M3R): a toolset for automated detection, localization, and monitoring of marine mammals in open ocean environments. Mar Technol Soc J 48:5-20

Johnson M, Madsen PT, Zimmer WMX, Aguilar de Soto N, Tyack PL (2004) Beaked whales echolocate on prey. Proc R Soc B 271:S383-S386

Johnson M, Hickmott LS, Aguilar de Soto N, Madsen PT (2008) Echolocation behaviour adapted to prey in foraging Blainville's beaked whale (Mesoplodon densirostris). Proc R Soc B 275:133-139

Joyce TW, Durban JW, Claridge DE, Dunn CA and others (2019) Behavioral responses of satellite tracked Blainville's beaked whales (Mesoplodon densirostris) to mid-frequency active sonar. Mar Mamm Sci 36:29-46

Kates Varghese H, Miksis-Olds J, DiMarzio N, Lowell K, Linder E, Mayer L, Moretti D (2020) The effect of two $12 \mathrm{kHz}$ multibeam mapping surveys on the foraging behavior of Cuvier's beaked whales off of southern California. J Acoust Soc Am 147:3849-3858

King SL, Schick RS, Donovan C, Booth CG, Burgman M, Thomas L, Harwood J (2015) An interim framework for assessing the population consequences of disturbance. Methods Ecol Evol 6:1150-1158

MacLeod CD, Zuur AF (2005) Habitat utilization by Blainville's beaked whales off Great Abaco, northern Bahamas, in relation to seabed topography. Mar Biol 147: $1-11$

*MacLeod CD, Santos M, Pierce G (2003) Review of data on diets of beaked whales: evidence of niche separation and geographic segregation. J Mar Biol Assoc UK 83: 651-665

Maxwell SM, Hazen EL, Bograd SJ, Halpern BS and others (2013) Cumulative human impacts on marine predators. Nat Commun 4:2688

McCarthy E, Moretti D, Thomas L, DiMarzio N and others (2011) Changes in spatial and temporal distribution and vocal behavior of Blainville's beaked whales (Mesoplodon densirostris) during multiship exercises with midfrequency sonar. Mar Mamm Sci 27:E206-E226

McClatchie S, Macaulay GJ, Coombs RF (2003) A requiem for the use of $20 \log _{10}$ length for acoustic target strength with special reference to deep-sea fishes. ICES J Mar Sci 60:419-428
Menzies R (1965) Conditions for the existence of life on the abyssal sea floor. Oceanogr Mar Biol Annu Rev 3:195-210

Moline MA, Benoit-Bird KJ (2016) Sensor fusion and autonomy as a powerful combination for biological assessment in the marine environment. Robotics 5:4

Moline MA, Benoit-Bird KJ, O'Gorman D, Robbins IC (2015) Integration of scientific echosounders with an adaptable autonomous platform to extend our understanding of animals from the surface to the bathypelagic. J Atmos Ocean Technol 32:2173-2186

Moretti D (2019) Estimating the effect of mid-frequency active sonar on the population health of Blainville's beaked whales (Mesoplodon densirostris) in the Tongue of the Ocean. PhD dissertation, University of $\mathrm{St}$ Andrews

*Moretti D, Marques T, Thomas L, DiMarzio N and others (2010) A dive counting density estimation method for Blainville's beaked whale (Mesoplodon densirostris) using a bottom-mounted hydrophone field as applied to a Mid-Frequency Active (MFA) sonar operation. Appl Acoust 71:1036-1042

* Moretti D, Thomas L, Marques T, Harwood J, Diley A (2014) A risk function for behavioral disruption of Blainville's beaked whales (Mesoplodon densirostris) from mid-frequency active sonar. PLOS ONE 9:e85064

Myers RA, Worm B (2003) Rapid worldwide depletion of predatory fish communities. Nature 423:280-283

*New LF, Moretti DJ, Hooker SK, Costa DP, Simmons SE (2013) Using energetic models to investigate the survival and reproduction of beaked whales (family Ziphiidae). PLOS ONE 8:e68725

Richardson WJ, Greene CR Jr, Malme CI, Thomson DH (2013) Marine mammals and noise. Academic Press, New York, NY

Ripple WJ, Beschta RL (2007) Restoring Yellowstone's aspen with wolves. Biol Conserv 138:514-519

Roberts CM (2002) Deep impact: the rising toll of fishing in the deep sea. Trends Ecol Evol 17:242-245

* Robison BH (2004) Deep pelagic biology. J Exp Mar Biol Ecol 300:253-272

* Roman J, Altman I, Dunphy-Daly MM, Campbell C, Jasny M, Read AJ (2013) The Marine Mammal Protection Act at 40: status, recovery, and future of US marine mammals. Ann N Y Acad Sci 1286:29-49

* Sato M, Benoit-Bird KJ (2017) Spatial variability of deep scattering layers shapes the Bahamian mesopelagic ecosystem. Mar Ecol Prog Ser 580:69-82

Simmonds MP, Dolman SJ, Jasny M, Parsons E, Weilgart L, Wright AJ, Leaper R (2014) Marine noise pollutionincreasing recognition but need for more practical action. J Ocean Technol 9:71-90

* Smith AD, Brown CJ, Bulman CM, Fulton EA and others (2011) Impacts of fishing low-trophic level species on marine ecosystems. Science 333:1147-1150

Southall BL (2017) Noise. In: Wursig TH, Thewissen JGM, Kovacs KM (eds) Encyclopedia of marine mammals, $3^{\text {rd }}$ edn. Academic Press, New York, NY, p 637-645

* Southall BL, Benoit-Bird KJ, Moline MA, Moretti D (2019) Quantifying deep-sea predator-prey dynamics: implications of biological heterogeneity for beaked whale conservation. J Appl Ecol 56:1040-1049

Springer AM, Estes J, Van Vliet GB, Williams T and others (2003) Sequential megafaunal collapse in the North Pacific Ocean: An ongoing legacy of industrial whaling? Proc Natl Acad Sci USA 100:12223-12228 
Tyack PL, Miller EH (2002) Vocal anatomy, acoustic communication and echolocation. In: Hoelzel A (ed) Marine mammal biology: an evolutionary approach. Blackwell Science, Oxford, p 142-184

Tyack PL, Zimmer WM, Moretti D, Southall BL and others (2011) Beaked whales respond to simulated and actual navy sonar. PLOS ONE 6:e17009

Veit R, McGowan J, Ainley D, Wahl T, Pyle P (1997) Apex marine predator declines ninety percent in association with changing oceanic climate. Glob Change Biol 3: 23-28

Warburton K, Thomson C (2006) Costs of learning: the dynamics of mixed-prey exploitation by silver perch,

Editorial responsibility: Peter Corkeron,

Woods Hole, MA, USA

Reviewed by: M. Vecchione and 1 anonymous referee
Bidyanus bidyanus (Mitchell, 1838). Anim Behav 71: 361-370

Williams R, Wright AJ, Ashe E, Blight L and others (2015) Impacts of anthropogenic noise on marine life: publication patterns, new discoveries, and future directions in research and management. Ocean Coast Manage 115: $17-24$

* Worm B, Myers R (2003) Meta-analysis of cod-shrimp interactions reveals top-down control in oceanic food webs. Ecology 84:162-173

Žydelis R, Wallace BP, Gilman EL, Werner TB (2009) Conservation of marine megafauna through minimization of fisheries bycatch. Conserv Biol 23:608-616

Submitted: August 15, 2020

Accepted: October 1, 2020

Proofs received from author(s): November 6, 2020 